\title{
Annie Thébaud-Mony, Travailler peut nuire gravement à votre santé
}

\section{Thomas Coutrot}

\section{Q OpenEdition}

1 Journals

Édition électronique

URL : http://journals.openedition.org/travailemploi/4390

DOI : 10.4000/travailemploi.4390

ISSN : $1775-416 \mathrm{X}$

Éditeur

DARES - Ministère du Travail

\section{Édition imprimée}

Date de publication : 30 décembre 2007

Pagination : 108

ISSN : 0224-4365

\section{Référence électronique}

Thomas Coutrot, «Annie Thébaud-Mony, Travailler peut nuire gravement à votre santé », Travail et Emploi [En ligne], 112 | octobre-décembre 2007, mis en ligne le 05 novembre 2010, consulté le 22 septembre 2020. URL : http://journals.openedition.org/travailemploi/4390 ; DOI : https://doi.org/10.4000/ travailemploi.4390 


\section{Travailler peut nuire gravement à votre santé}

Annie Thébaud-Mony

La Découverte, 2007

\section{Lu par Thomas Coutrot (4)}

C'est un autre type de lien entre gestion de la main-d'œuvre et santé des travailleurs qu'éclaire crûment le livre d'Annie Thébaud-Mony: l'impact des stratégies de sous-traitance des risques. Puisant ses exemples dans de nombreux secteurs - le bâtiment, l'industrie nucléaire, l'équipement automobile, l'industrie navale..., elle montre en recoupant de multiples témoignages et enquêtes, comment les réorganisations des entreprises autour de leur cœur de métier et le recours accru à la filialisation et à la sous-traitance ont pour effet à la fois d'accroître les risques et de diluer les responsabilités en matière d'accidents du travail et de maladies professionnelles. L'exemple d'AZF Toulouse, où intérimaires et salariés d'entreprises sous-traitantes sont nombreux parmi les victimes, est le plus célèbre: dans l'usine travaillaient 1700 salariés dont 1000 intérimaires et sous-traitants. On connaît aussi les pratiques des pavillons de complaisance qui permettent aux armateurs de rémunérer les marins à des tarifs très compétitifs, mais sans garanties pour la sécurité et l'environnement.

L'un des chapitres les plus passionnants du livre d'Annie Thébaud-Mony est consacré à la «délocalisation de la mort au travail», où les industriels de l'amiante - mais aussi, de façon étonnante et finement analysée, certains syndicats comme dans le cas du Québec - tiennent le premier rôle, par leurs stratégies sans cesse renouvelées pour prolonger la vie économique de ce produit mortel. L'auteure est à la fois une sociologue experte des risques professionnels et une militante inventive, à l'origine (avec d'autres) de la création d'une ONG internationale pour l'interdiction mondiale de l'amiante, Ban Asbestos. L'action de cette association illustre ces alliances typiques de la "mondialisation par en bas », par laquelle mouvements sociaux et chercheurs critiques des dérives de la technoscience s'opposent ensemble à des logiques économiques aveugles. Le clou du livre est sans doute le récit du haut fait de Ban Asbestos, le retour forcé du porteavions Clemenceau, qui avait été expédié en Inde par le gouvernement français pour y être démantelé; la Cour suprême indienne a jugé qu'il y avait là une violation des conventions internationales sur le traitement des déchets toxiques.
Alors que certains chercheurs travaillent avec les mouvements sociaux, d'autres scientifiques, que l'auteure désigne, ont collaboré avec l'industrie de l'amiante pour retarder les mesures d'interdiction. Le récit de la carrière de Richard Doll, épidémiologiste talenteux devenu progressivement la caution scientifique du lobby international de l'amiante, est à la fois effrayant et édifiant sur les liens qui s'établissent parfois entre mondes scientifique et industriel.

On peut cependant regretter que l'auteure tende à s'appuyer sur ce qui est manifestement une dérive personnelle - de la part d'un épidémiologiste certes éminent-pour condamner en bloc l'épidémiologie, qu'elle va jusqu'à qualifier de science de "l'expérimentation humaine». Selon A. ThébaudMony, au lieu d'invoquer le principe de précaution pour justifier le retrait des produits dont la toxicité est établie par l'expérimentation animale ou par des travaux de toxicologie, les épidémiologistes accepteraient que des populations restent exposées à certains risques, pour pouvoir analyser statistiquement les différences de morbidité ou de mortalité entre populations exposées et échantillons témoins. On peut au contraire juger que l'épidémiologie, à condition qu'elle reconnaisse leur place aux autres méthodes (y compris d'ailleurs la sociologie des risques professionnels...), joue un rôle indispensable parmi les disciplines scientifiques qui permettent de comprendre les effets des expositions à divers risques professionnels, qu'ils soient d'ailleurs chimiques, physiques ou organisationnels. Reprocher aux épidémiologistes de ne pas rechercher «le consentement des travailleurs et des populations exposées aux risques, ainsi transformées en cobayes », est assez injuste quand la plupart des recueils de données se font a posteriori, via la reconstitution d'expositions passées au cours de la carrière des personnes. Ou bien quand les facteurs de risques analysés sont de nature organisationnelle et psychosociale, en lien avec les nouveaux modes d'organisation du travail. L'épidémiologie est bien souvent indispensable pour tirer la sonnette d'alarme et alerter sur les responsabilités.

Le livre d'Annie Thébaud-Mony, nourri par de nombreux cas concrets et éclairants, n'en demeure pas moins une référence obligée pour ceux qui veulent comprendre les enjeux de la sous-traitance des risques sur la santé des travailleurs, en Europe et dans le monde. 